\title{
COMPORTAMENTO DE ATRIBUTOS FÍSICOS DE UM LATOSSOLO AMARELO SOB AGROECOSSISTEMAS DO AMAZONAS ${ }^{1}$
}

\author{
ZIGOMAR M. SOUZA ${ }^{2}$, JOSÉ A. LEITE ${ }^{3}$, AMAURI N. BEUTLER ${ }^{2}$
}

\begin{abstract}
RESUMO: O desmatamento da floresta tropical da Amazônia e a utilização do solo para fins agrícolas potencializam sua degradação física, química e biológica, quando realizados de forma inadequada. Este estudo teve o objetivo de avaliar o efeito de sistemas de uso e manejo de um Latossolo Amarelo, muito argiloso, mediante avaliações de atributos físicos determinados nas profundidades de 0,0-0,2 e 0,2-0,4 m, em área da Universidade do Amazonas, Manaus (AM). Os sistemas de uso e manejo foram: milho, laranja, pupunha, guaraná, pastagem, capoeira e floresta. Nos sistemas com milho, laranja, pupunha e pastagem, foram realizados o desmatamento, a queima e as operações de preparo e cultivo mecanizados. Foram avaliados a composição granulométrica, o grau de floculação da argila, o teor de matéria orgânica, a densidade de partículas, a densidade do solo, a porosidade total, a macro e microporosidade, e a infiltrações inicial e básica. Utilizou-se o delineamento experimental inteiramente casualizado, com três repetições. Os agroecossistemas, em ordem crescente: capoeira, guaraná, milho, laranja, pupunha e pastagem induziram uma degradação dos atributos físicos do solo cultivado em relação ao de floresta, quantificada pelos maiores valores de densidade do solo e menores de macroporosidade, infiltração de água e matéria orgânica.
\end{abstract}

PALAVRAS-CHAVE: matéria orgânica, propriedades físicas, sistemas de uso.

\section{CHANGES IN PHYSICAL ATTRIBUTES OF A YELLOW LATOSOL UNDER AGROECOSSYSTEMS IN AMAZONAS STATE, BRAZIL}

SUMMARY: The Amazon tropical forest deforestation and the agricultural use of soils can lead to soil physical, chemical and biological degradation. This study evaluated land use and tillage systems in Yellow Latosol, very clayey, by physical attributes determinated in 0.0-0.2 and 0.2-0.4 m depths, in Universidade do Amazonas, Manaus (AM). The land used and tillage systems were: corn, orange, peach palm, guarana, pasture, capoeira and forest. Deforestation, slash-burning and mechanizated operation of tillage and manage were used on corn, orange, peach palm and pasture systems. Soil properties (particle size, clay flocculation degree, organic matter, particle density, bulk density, total porosity, macro and microporosity, initial and basic infiltration) were evaluated after 6 to 12 years of management. The experiment was a completely randomized design with three replicates. Capoeira, guarana, corn, orange, peach palm and pasture, in this order, induced soil physical attributes degradation compared with forest, presented greater values of soil bulk density and lowest macroporosity, water infiltration and organic matter.

KEYWORDS: organic matter, physical properties, use systems.

\footnotetext{
${ }^{1}$ Trabalho desenvolvido na Universidade Federal do Amazonas - UA.

${ }^{2}$ Alunos de Doutorado do Curso de Agronomia/Produção Vegetal, Universidade Estadual Paulista, FCAV/UNESP, Departamento de Solos e Adubos, Jaboticabal - SP, e-mail: zigomar@fcav.unesp.br, amaurib@yahoo.com.br. Bolsista da FAPESP.

${ }^{3}$ Professor Titular, Universidade Federal do Amazonas, Faculdade de Ciências Agrárias, Manaus - AM.

Recebido pelo Conselho Editorial em: 3-2-2003

Aprovado pelo Conselho Editorial em: 20-10-2004
} 


\section{INTRODUÇÃO}

A grande área de florestas naturais ainda existente no Brasil está localizada na Amazônia e permaneceu praticamente intocada, em sua cobertura vegetal, até a década de 1960. De acordo com dados recentes, a Amazônia apresenta 12,9\% de seu território alterado (AGRIANUAL, 2002), em consequiência das ações antrópicas. Parte dessa alteração é decorrente da implantação de atividades agrícolas estimuladas por incentivos governamentais nas décadas de 1970 e 1980. É previsível que solos sob vegetação natural apresentem determinadas características que são modificadas quando passam a ser utilizados para outros fins. A mecanização agrícola, em busca de uma produtividade cada vez maior, é um dos principais fatores que têm contribuído, em grande escala, para a degradação dos recursos naturais, principalmente a estrutura do solo.

O cultivo intensivo do solo e o seu preparo em condições inadequadas alteram suas características físicas em graus variáveis, o que ocorre no Estado do Amazonas, principalmente nas áreas próximas de Manaus, onde o preparo mecanizado é realizado muitas vezes de forma indiscriminada. Tal prática, associada às precipitações pluvimométricas intensas que ocorrem nessa região, na época de preparo do solo e no crescimento inicial das plantas, constituem fatores responsáveis pela degradação da estrutura e formação de camadas compactadas. As principais alterações evidenciam-se por modificações nos valores de densidade do solo, porosidade total, distribuição do diâmetro dos poros e porosidade de aeração, armazenamento e disponibilidade de água às plantas, infiltração de água, agregação e teor de matéria orgânica (LEITE, 1996; KLEIN et al., 1998; CARVALHO et al., 1999; LONGO, 1999; MELLO IVO \& MIELNICZUK, 1999).

Sendo o Latossolo Amarelo muito argiloso e de grande expressão geográfica na região amazônica, cuja exploração desordenada pode levar a acentuadas quedas na produtividade das culturas, o presente trabalho teve como objetivo avaliar as modificações dos seus atributos físicos, quando submetido a diferentes sistemas de uso e manejo, comuns na Amazônia.

\section{MATERIAL E MÉTODOS}

O estudo foi conduzido na Fazenda de Ensino e Pesquisa da Faculdade de Ciências Agrárias da Universidade do Amazonas, situada à margem esquerda da Rodovia BR-174 (km 38), Manaus -AM, localizada nas coordenadas geográficas $2^{\circ} 54^{\prime} \mathrm{S}$ e $60^{\circ} 01^{\prime} \mathrm{W}$. O tipo climático, segundo Köeppen, é Af, caracterizado por apresentar temperatura do mês mais frio sempre superior a $18{ }^{\circ} \mathrm{C}$, precipitação pluvial do mês mais seco superior a $60 \mathrm{~mm}$ e precipitação média anual de $2.400 \mathrm{~mm}$.

O solo foi classificado como Latossolo Amarelo álico, textura muito argilosa (RODRIGUES et al., 1971) e atualmente classificado, segundo EMBRAPA (1999), como Latossolo Amarelo, distrófico, típico, muito argiloso, A moderado, álico, caulinítico, muito profundo, ácido (LAd).

Os tratamentos estudados foram: 1 - milho (Zea mays L.) em sistema de preparo convencional, com uma aração e uma gradagem e controle químico de invasoras (12 anos); 2 - laranja (Citrus spp.) em sistema de preparo convencional, com uma aração, uma gradagem e tratos culturais mecanizados e controle de invasoras com roçagem (10 anos); 3 - pupunha (Bractris gasipaes H.B.K.) em sistema de preparo convencional, com uma aração, uma gradagem e tratos culturais mecanizados e controle manual de invasoras (10 anos); 4 - guaraná (Paullinia cupana var. sorbilis (Mart.) Ducke), com implantação e tratos culturais efetuados manualmente (9 anos); 5 - pastagem (Brachiaria humidicola) em área com superlotação animal (12 anos); 6 - capoeira em área desmatada, porém não cultivada (6 anos), e 7 - floresta tropical natural, úmida. Cada tratamento teve uma área útil de $600 \mathrm{~m}^{2}$, e os sistemas de uso foram conduzidos na forma de monocultivo durante todos anos para o milho, laranja, pupunha e pastagem; a floresta natural foi desmatada mecanicamente e queimada, e, nos sistemas com guaraná e capoeira, realizaram-se o desmatamento manual e a queima. Efetuou-se a calagem antes da 
instalação da cultura do milho, laranja, pupunha, guaraná e pastagem para elevar a saturação por bases a $60 \%$, sendo realizada na área com milho, laranja, pupunha e guaraná, adubação anual de $400 \mathrm{~kg} \mathrm{ha}^{-1}$, da fórmula 4-30-20, seguindo-se a recomendação para as culturas no Amazonas.

Em setembro de 1997, foram coletadas amostras nas profundidades de 0,0-0,2 e 0,2-0,4 m, com três repetições e cinco subamostras por repetição, para as seguintes determinações: caracterização granulométrica, por dispersão $\operatorname{com~} \mathrm{NaOH}\left(0,1 \mathrm{~mol} \mathrm{~L}^{-1}\right)$ e agitação lenta durante $16 \mathrm{~h}$, sendo o conteúdo de areia obtido por peneiramento, a argila pelo método da pipeta e o silte por diferença (EMBRAPA, 1979). Para a determinação do grau de floculação, não se utilizou dispersante químico, sendo obtido a partir da expressão (argila total - argila dispersa em água)/argila total. O teor de matéria orgânica foi determinado conforme o procedimento descrito por VETTORI (1969).

A densidade de partículas foi obtida pelo método do balão volumétrico (FORSYTHE, 1971) e a densidade do solo, pelo método do torrão parafinado descrito por BLAKE (1965). Em amostras indeformadas coletadas com anéis volumétricos foram determinadas a microporosidade por secamento (0,006 MPa), em câmaras de pressão de Richards com placa porosa (KLUTE, 1986), e a porosidade total, segundo DANIELSON \& SUTHERLAND (1986), sendo a macroporosidade obtida por diferença entre a porosidade total e a microporosidade. A infiltração de água no solo foi determinada pelo método de cilindro infiltrômetro (BERTRAND, 1965).

Os efeitos dos sistemas de uso e manejo do solo sobre as propriedades físicas em cada profundidade foram verificados a partir da análise de variância, seguindo-se um delineamento inteiramente casualizado, com três repetições. A diferença entre as médias foi avaliada pelo teste de Tukey, a $5 \%$ de probabilidade.

\section{RESULTADOS E DISCUSSÃO}

Na Tabela 1, verifica-se elevado grau de floculação desse solo, confirmando os estudos de MEDINA (1980) e LEITE \& MEDINA (1984). Isso se deve ao alto conteúdo de argila desse solo, que é originado a partir do argilito, bem como um avançado estágio de intemperização. Dessa forma, segundo LEITE (1996), é provável que os óxidos hidratados de ferro e alumínio, comumente abundantes nesses solos, façam com que essa classe de solo apresente esse alto grau de floculação, bem como a matéria orgânica humificada, cujos componentes devem promover forte agregação das partículas minerais.

Pode-se observar na Tabela 1, na profundidade de 0,0-0,2 m, que os sistemas capoeira e floresta apresentaram os maiores valores de matéria orgânica, seguido pelo sistema com guaraná. Os sistemas com milho, pupunha, laranja e pastagem apresentaram os menores valores, não diferindo estatisticamente entre si. Em geral, o mesmo comportamento foi observado na profundidade de 0,2-0,4 m, mostrando o efeito negativo da mecanização no teor de matéria orgânica, uma vez que os sistemas não mecanizados (guaraná e capoeira) apresentaram valores próximos aos da floresta. Corroborando essa constatação, MELLO IVO \& MIELNICZUK (1999) verificaram menores teores de matéria orgânica em sistemas de preparo convencional, e CENTURION et al. (2001) observaram decréscimo dos teores de matéria orgânica nas profundidades de 0,0-0,2 $\mathrm{m}$ e 0,2-0,4 $\mathrm{m}$, quando se comparam a mata e os diferentes sistemas de exploração. Esses autores afirmam que isso ocorre porque, em sistemas sob cultivo, o revolvimento dos solos aumenta a aeração, favorecendo a mineralização da matéria orgânica.

Os valores superiores de matéria orgânica na camada de 0,0-0,2 m estão relacionados ao acúmulo de restos vegetais na superfície do solo, o que também foi constatado por LEITE (1996), CARVALHO et al. (1999) e LONGO (1999), bem como pela natureza superficial das raízes da maioria dos vegetais (SANCHEZ, 1981). 
TABELA 1. Composição granulométrica, grau de floculação (GF) e matéria orgânica (MO) para os sistemas de uso e manejo, em duas profundidades.

\begin{tabular}{|c|c|c|c|c|c|c|c|}
\hline \multirow[b]{2}{*}{$\begin{array}{l}\text { Sistema } \\
\text { de Uso }\end{array}$} & \multicolumn{5}{|c|}{ Composição Granulométrica } & \multirow[b]{2}{*}{$\begin{array}{l}\text { GF } \\
(\%)\end{array}$} & \multirow[b]{2}{*}{$\begin{array}{c}\mathrm{MO} \\
\left(\mathrm{g} \mathrm{dm}^{-3}\right)\end{array}$} \\
\hline & Areia Grossa & Areia Fina & $\frac{\text { Areia Total }}{\mathrm{g} \mathrm{kg}^{-1}}$ & Silte & Argila & & \\
\hline \multicolumn{8}{|c|}{$0,0-0,2 \mathrm{~m}$} \\
\hline Milho & 110 & 30 & 140 & 150 & 710 & 88,1 & $29,4 \mathrm{c}$ \\
\hline Laranja & 110 & 30 & 140 & 220 & 640 & 87,9 & $27,9 \mathrm{c}$ \\
\hline Pupunha & 60 & 20 & 80 & 160 & 760 & 88,4 & $24,3 \mathrm{c}$ \\
\hline Guaraná & 110 & 30 & 140 & 180 & 680 & 85,7 & $35,8 \mathrm{~b}$ \\
\hline Pastagem & 110 & 30 & 140 & 140 & 720 & 89,2 & $26,1 \mathrm{c}$ \\
\hline Capoeira & 100 & 30 & 130 & 200 & 670 & 86,5 & $39,8 \mathrm{a}$ \\
\hline Floresta & 110 & 30 & 140 & 210 & 650 & 85,4 & $40,1 \mathrm{a}$ \\
\hline \multicolumn{8}{|c|}{$0,2-0,4 \mathrm{~m}$} \\
\hline Milho & 90 & 20 & 110 & 190 & 700 & 86,7 & $20,5 \mathrm{c}$ \\
\hline Laranja & 80 & 20 & 100 & 210 & 690 & 88,7 & $19,8 \mathrm{~cd}$ \\
\hline Pupunha & 100 & 30 & 130 & 160 & 710 & 89,8 & $17,4 \mathrm{~cd}$ \\
\hline Guaraná & 100 & 30 & 130 & 170 & 700 & 87,8 & $28,0 \mathrm{a}$ \\
\hline Pastagem & 90 & 20 & 110 & 160 & 730 & 88,3 & $21,2 \mathrm{c}$ \\
\hline Capoeira & 80 & 30 & 110 & 160 & 730 & 89,0 & $24,3 \mathrm{~b}$ \\
\hline Floresta & 120 & 30 & 150 & 220 & 630 & 88,5 & $27,2 \mathrm{a}$ \\
\hline
\end{tabular}

Médias seguidas pela mesma letra na coluna, na mesma profundidade, não diferem estatisticamente entre si, pelo teste de Tukey $(\mathrm{P} \leq 0,05)$.

A densidade de partículas foi menor nos sistemas de uso e manejo não mecanizados (Tabela 2) em relação ao milho, pupunha e pastagem, nas duas profundidades. Isso ocorreu devido aos maiores conteúdos de matéria orgânica, cujo baixo peso específico contribuiu para diminuir a densidade de partículas. Esses valores concordam com os resultados obtidos por LEITE \& MEDINA (1984) e LEITE (1996), em sistemas de manejo em Latossolo Amarelo do Amazonas. Nesse contexto, REICHARDT (1975) afirma que a densidade de partículas é pouco influenciada pelo preparo do solo.

Pelos valores de densidade do solo e porosidade (Tabela 2), observa-se que os sistemas de uso com milho, guaraná, capoeira e floresta apresentaram os menores valores de densidade do solo, na camada de 0,0-0,2 m. Esse fato demonstra menor grau de compactação desses sistemas em relação à pupunha e laranja, os quais requerem tráfego constante de máquinas para a realização dos tratos culturais. Esses resultados são concordantes com os obtidos por CARVALHO et al. (1999) e BEUTLER et al. (2001), estudando o efeito de sistemas de preparo mecanizado, os quais encontraram valores bem maiores de densidade do solo em relação às áreas não mecanizadas, na camada superficial. Já a macroporosidade foi superior apenas nos sistemas de floresta, guaraná e capoeira não mecanizados, o que deve estar também relacionado a agregados maiores, estáveis em água.

O sistema de pastagem com superpastejo é o que apresentou maior valor de densidade do solo. Isso ocorre, segundo PETERSON (1970), devido ao pisoteio de animais (bovinos) que apresentam peso corpóreo muito grande e a área da pata pequena, que, ao caminharem pelos pastos, imprimem sobre o solo elevadas pressões, compactando-o até 0,10 a $0,15 \mathrm{~m}$ de profundidade. 
TABELA 2. Valores médios $(n=3)$ de densidade de partículas (Dp), densidade do solo (Ds), macroporosidade, microporosidade e porosidade total $(\mathrm{Pt})$ nos sistemas de uso e manejo, em duas profundidades.

\begin{tabular}{|c|c|c|c|c|c|}
\hline \multirow{2}{*}{$\begin{array}{l}\text { Sistema } \\
\text { de Uso }\end{array}$} & $\mathrm{Dp}$ & Ds & Macroporos & Microporos & $\mathrm{Pt}$ \\
\hline & \multicolumn{2}{|c|}{$\mathrm{kg} \mathrm{dm}^{-3} \longrightarrow$} & \multicolumn{3}{|c|}{$\mathrm{m}^{3} \mathrm{~m}^{-3}$} \\
\hline \multicolumn{6}{|c|}{$0,0-0,2 \mathrm{~m}$} \\
\hline Milho & $2,57 \mathrm{a}$ & $1,26 \mathrm{~b}$ & $0,09 \mathrm{c}$ & $0,42 \mathrm{a}$ & $0,51 \mathrm{~b}$ \\
\hline Laranja & $2,50 \mathrm{~b}$ & $1,32 \mathrm{a}$ & $0,09 \mathrm{c}$ & $0,38 \mathrm{a}$ & $0,47 \mathrm{~b}$ \\
\hline Pupunha & $2,59 \mathrm{a}$ & $1,33 \mathrm{a}$ & $0,08 \mathrm{c}$ & $0,41 \mathrm{a}$ & $0,49 \mathrm{~b}$ \\
\hline Guaraná & $2,53 \mathrm{~b}$ & $1,23 \mathrm{~b}$ & $0,11 b$ & $0,42 \mathrm{a}$ & $0,53 \mathrm{a}$ \\
\hline Pastagem & $2,58 \mathrm{a}$ & $1,35 \mathrm{a}$ & $0,07 \mathrm{c}$ & $0,41 \mathrm{a}$ & $0,48 \mathrm{~b}$ \\
\hline Capoeira & $2,52 \mathrm{~b}$ & $1,19 b$ & $0,13 \mathrm{~b}$ & $0,39 \mathrm{a}$ & $0,53 \mathrm{a}$ \\
\hline Floresta & $2,49 \mathrm{~b}$ & $1,09 \mathrm{c}$ & $0,18 \mathrm{a}$ & $0,38 \mathrm{a}$ & $0,56 \mathrm{a}$ \\
\hline \multicolumn{6}{|c|}{$0,2-0,4 \mathrm{~m}$} \\
\hline Milho & $2,59 \mathrm{a}$ & $1,33 \mathrm{~b}$ & $0,07 \mathrm{~cd}$ & $0,41 \mathrm{a}$ & $0,47 \mathrm{~b}$ \\
\hline Laranja & $2,58 \mathrm{ab}$ & $1,36 a b$ & $0,08 \mathrm{bc}$ & $0,39 \mathrm{a}$ & $0,44 \mathrm{~b}$ \\
\hline Pupunha & $2,65 \mathrm{a}$ & $1,39 \mathrm{a}$ & $0,07 \mathrm{~cd}$ & $0,41 \mathrm{a}$ & $0,45 \mathrm{~b}$ \\
\hline Guaraná & $2,56 b$ & $1,32 \mathrm{~b}$ & $0,09 \mathrm{~b}$ & $0,40 \mathrm{a}$ & $0,50 \mathrm{a}$ \\
\hline Pastagem & $2,61 \mathrm{a}$ & $1,40 \mathrm{a}$ & $0,05 \mathrm{e}$ & $0,40 \mathrm{a}$ & $0,45 \mathrm{~b}$ \\
\hline Capoeira & $2,56 \mathrm{~b}$ & $1,25 \mathrm{c}$ & $0,11 \mathrm{~b}$ & $0,40 \mathrm{a}$ & $0,51 \mathrm{a}$ \\
\hline Floresta & $2,51 \mathrm{c}$ & $1,19 \mathrm{~d}$ & $0,16 \mathrm{a}$ & $0,38 \mathrm{a}$ & $0,53 \mathrm{a}$ \\
\hline
\end{tabular}

Médias seguidas pela mesma letra na coluna, na mesma profundidade, não diferem estatisticamente entre si, pelo teste de Tukey $(\mathrm{P} \leq 0,05)$.

A densidade do solo na área com milho não diferiu das áreas com guaraná e capoeira, na profundidade de 0,0-0,2 m, com valores inferiores à laranja, pupunha e pastagem. Esse resultado na área com milho ocorre graças às operações de preparo, com uma aração e uma gradagem, que revolvem anualmente o solo e na área com guaraná e capoeira devido à não-mecanização. Na laranja e pupunha, o tráfego de máquinas para a realização dos tratos culturais aumentou os valores de densidade, confirmando os estudos de SALIRE et al. (1994) e HAKANSSON \& VOORHEES (1997), que afirmam que o tráfego de máquinas sobre o solo aumenta a densidade. Entretanto, esse efeito é menos evidente na profundidade de 0,2-0,4 m, concordando com estudos de BEUTLER et al. (2001).

A macroporosidade nos sistemas de uso com guaraná e capoeira não diferiu na camada de 0,0 $0,2 \mathrm{~m}$, com valores superiores aos sistemas mecanizados, sendo observado comportamento semelhante na camada de 0,2-0,4 m. Nos sistemas mecanizados com milho, pupunha, laranja e pastagem, foram encontrados valores de macroporosidade inferiores a $0,1 \mathrm{~m}^{3} \mathrm{~m}^{-3}$ que, segundo ERICKSON (1984), constitui a necessidade mínima de porosidade de aeração para o crescimento radicular da maioria das culturas. Os sistemas de guaraná e capoeira foram os que apresentaram valores de densidade do solo e macroporosidade mais próximos à floresta nativa, em ambas as profundidades.

A porosidade total nos sistemas de uso com guaraná, capoeira e floresta não apresentou diferença nas profundidades de 0,0-0,2 $\mathrm{m}$ e 0,2-0,4 $\mathrm{m}$ e valores superiores aos sistemas mecanizados, confirmando os estudos de SILVA \& MIELNICZUK (1997), CAVENAGE et al. (1999) e BEUTLER et al. (2001). Entretanto, o efeito da ação antrópica foi refletido em aumento da densidade do solo, a qual afetou a macroporosidade, não alterando a microporosidade, confirmando os estudo de DA ROS et al. (1997), CAVENAGE et al. (1999) e BEUTLER et al. (2001), os quais verificaram que a redução da porosidade total é caracterizada inicialmente pela redução da macroporosidade. 
A diminuição da porosidade total e o aumento da relação microporosidade/macroporosidade mostram o surgimento de camadas compactadas, como ocorreu nas áreas de milho, pupunha, laranja e pastagem, concordando com os resultados de CORREAA (1985), em Latossolo Amarelo do Amazonas.

Verificou-se grande variabilidade dos valores de infiltração inicial e básica de água no solo, confirmada pelo coeficiente de variação próximo a 30\%, concordando com ARZENO (1990), que encontrou alta variabilidade da infiltração e afirma que é característica típica das propriedades de movimentação tridimensional da água no solo. Apesar disso, foi possível diferenciar os agroecossistemas em relação à infiltração de água.

Na Figura 1, observa-se que os maiores valores de infiltração inicial e básica foram obtidos no solo sob floresta, seguidos pelos sistemas de uso com guaraná e capoeira, os quais não diferiram entre si. Esses resultados estão coerentes com os menores valores de densidade do solo e maiores de macroporosidade, concordando com os estudos de LEITE \& MEDINA (1984), CORREAA (1985), CAVENAGE et al. (1999) e CENTURION et al. (2001), em sistemas de uso e manejo. Segundo CASTRO \& VIEIRA (1996), a maior infiltração de água nos sistemas não mecanizados, comparada aos mecanizados, ocorre devido à quantidade, continuidade e tamanho dos poros que são responsáveis pela infiltração de água no solo.

Os maiores valores de infiltração nos sistemas com guaraná, capoeira e floresta devem-se à influência dos atributos físicos do solo, haja vista que os teores de água do solo não apresentaram diferença significativa entre os sistemas de uso (Figura 1).

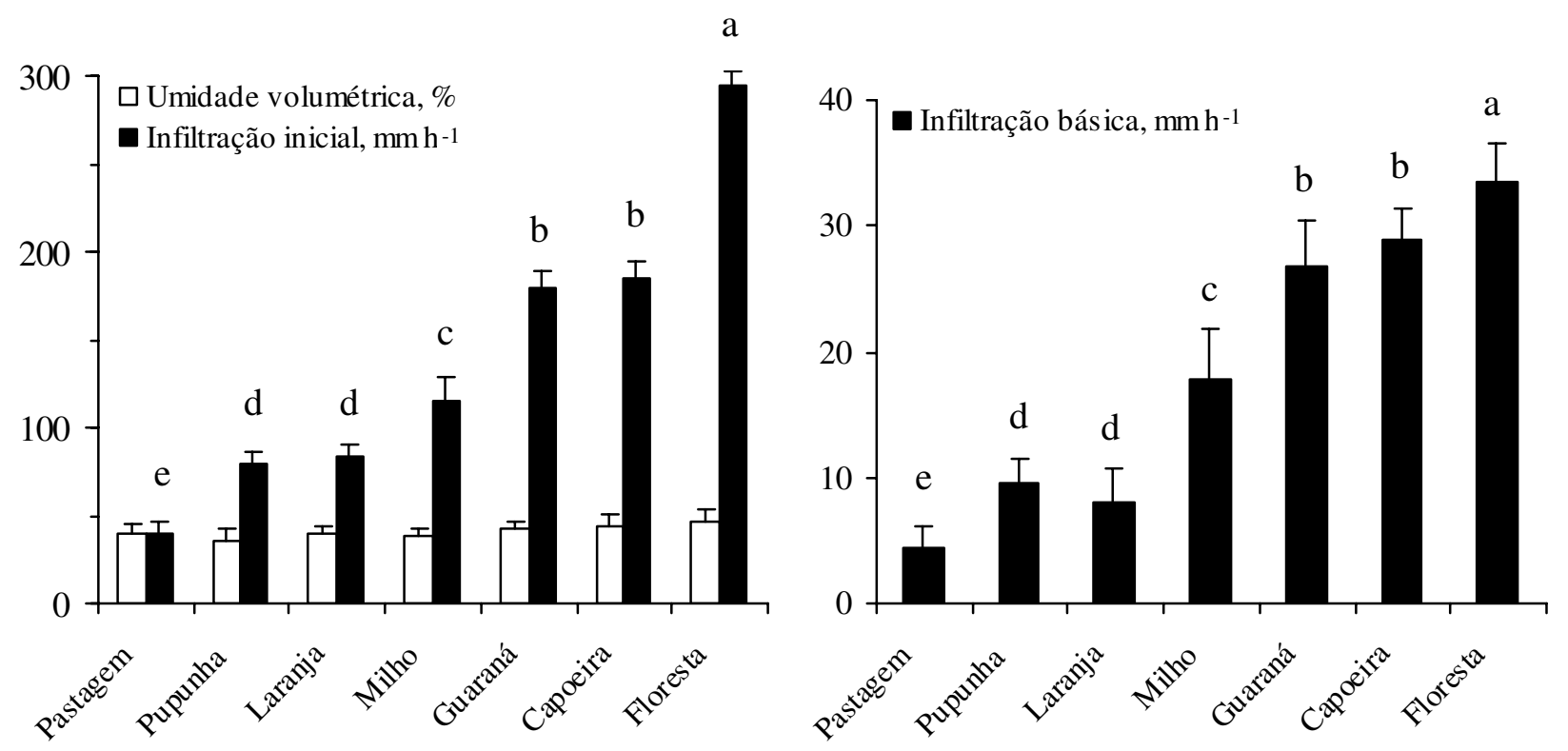

FIGURA 1. Valores médios $(n=3)$ com respectivo desvio-padrão da umidade volumétrica $(\%)$, infiltração inicial de água $\left(\mathrm{mm} \mathrm{h}^{-1}\right)$ e infiltração básica $\left(\mathrm{mm} \mathrm{h}^{-1}\right)$ no Latossolo VermelhoAmarelo em sistemas de uso. Médias seguidas da mesma letra, para o mesmo atributo, não diferem entre si $(\mathrm{P} \leq 0,05)$.

Os sistemas com milho, pupunha, laranja e pastagem apresentaram valores inferiores para infiltração inicial e básica de água no solo, com destaque para o sistema com pastagem, o qual apresentou maior densidade do solo e menor macroporosidade. Observa-se, ainda, que o sistema milho com revolvimento anual do solo apresentou maior infiltração em relação à laranja e pupunha, coerente com o menor valor de densidade do solo. 
A infiltração de água no solo indica diferenças no comportamento hidrodinâmico do solo em função da alteração de sua estrutura. Assim, considerando-se que a infiltração de água reflete bem as condições físicas do solo, tais como a estrutura, a porosidade e a presença de camadas compactadas, pode-se inferir que, no solo estudado, elas sofreram modificações em função do uso e manejo. A taxa de infiltração inicial e infiltração básica decresceu nos sistemas de manejo em relação à floresta natural, concordando com os resultados obtidos por TREIN et al. (1991), ANJOS et al. (1994) e CENTURION et al. (2001). De acordo com a classificação de REICHARDT (1987) para infiltração básica de água no solo, no solo sob floresta, foi classificada como muito alta, seguido do guaraná e capoeira sem mecanização, e milho com revolvimento anual classificados como alta; laranja e pupunha com cultivo mecanizado como média, e pastagem como baixa.

\section{CONCLUSÕES}

Os agroecossistemas caracterizados no Latossolo Amarelo muito argiloso da Universidade do Amazonas induziram a degradação dos atributos físicos do solo em relação à floresta, quantificada a partir de maiores valores de densidade do solo e menores de macroporosidade, infiltração de água e matéria orgânica, na seguinte ordem crescente: capoeira, guaraná, milho, laranja, pupunha e pastagem.

O solo sem mecanização, com sistemas de uso com capoeira e guaraná, apresentou melhores condições de qualidade, pois a matéria orgânica manteve-se em níveis similares à floresta nativa e com menores alterações nos atributos físicos do solo, comparado aos demais sistemas de uso.

A ação antrópica de derruba manual da floresta foi suficiente para promover alteração nos atributos físicos do solo, demonstrado na área com capoeira em relação à floresta natural.

\section{REFERÊNCIAS}

AGRIANUAL 2002: anuário da agricultura brasileira. São Paulo: FNP Consultoria e Comércio, $2001.536 \mathrm{p}$.

ANJOS, J.T.; UBERTI, A.A.A.; VIZZOTTO, V.J.; LEITE, G.B.; KRIEGER, M. Propriedades físicas em solos sob diferentes sistemas de uso e manejo. Revista Brasileira de Ciência do Solo, Campinas, v.18, n.1, p.139-45, 1994.

ARZENO, J.L. Avaliação física de diferentes manejos de solo em um Latossolo Roxo distrófico. 1990. 259 f. Tese (Doutorado em Solos e Nutrição de Plantas) - Escola Superior de Agricultura "Luiz de Queiroz”, Universidade de São Paulo, Piracicaba, 1990.

BERTRAND, A.R. Rate of water intake in the field. In: BLACK, C.A. (Ed.). Methods of soil analysis. Madison: American Society of Agronomy, 1965. p.197-208.

BEUTLER, A.N.; SILVA, M.L.N.; CURI, N.; FERREIRA, M.M.; CRUZ, J.C.; PEREIRA FILHO, I.A. Resistência à penetração e permeabilidade de Latossolo Vermelho distrófico típico sob sistemas de manejo na região dos cerrados. Revista Brasileira de Ciência do Solo, Viçosa, v.25, n.1, p.167-77, 2001.

BLAKE, G.R. Bulk density. In: BLACK, C.A. (Ed.). Methods of soil analysis. Madison: American Society of Agronomy, 1965. p.374-90.

CARVALHO, E.J.M.; FIGUEIREDO, M.S.; COSTA, L.M. Comportamento físico-hídrico de um Podzólico Vermelho-Amarelo Câmbico fase terraço sob diferentes sistemas de manejo. Pesquisa Agropecuária Brasileira, Brasília, v.34, n.2, p.257-65, 1999. 
CASTRO, O.M.; VIEIRA, S.R. Condutividade hidráulica de um Latossolo Roxo sob três sistemas de preparo. In: CONGRESSO LATINO-AMERICANO DE CIÊNCIA DO SOLO, 13., 1996, Águas de Lindóia. Anais... Águas de Lindóia: Sociedade Brasileira de Ciência do Solo, 1996. 1 CD ROM.

CAVENAGE, A.; MORAES, M.L.T.; ALVES, M.C.A.; CARVALHO, M.A.C.; FREITAS, M.L.M.; BUZETTI, S. Alterações nas propriedades físicas de um Latossolo Vermelho-Escuro sob diferentes culturas. Revista Brasileira de Ciência do Solo, Viçosa, v.23, n.4, p.997-1003, 1999.

CENTURION, J.F.; CARDOSO, J.P.; NATALE, W. Efeito de formas de manejo em algumas propriedades físicas e químicas de um Latossolo Vermelho em diferentes agroecossistemas. Revista Brasileira de Engenharia Agrícola e Ambiental, Campina Grande, v.5, n.2, p.254-8, 2001.

CORRÊA, J.C. Características físicas de um Latossolo Amarelo muito argiloso. Pesquisa Agropecuária Brasileira, Brasília, v.20, n.12, p.1381-7, 1985.

DANIELSON, R.E.; SUTHERLAND, P.L. Porosity. In: KLUTE, A. (Ed.) Methods of soil analysis. 2.ed. Madison: American Society of Agronomy, 1986. p.443-61.

DA ROS, C.O.; SECCO, D.; FIORIN, J.E.; PETRERE, C.; CADORE, M.A.; PASA, L. Manejo do solo a partir de campo nativo: efeito sobre a forma e estabilidade da estrutura ao final de cinco anos. Revista Brasileira de Ciência do Solo, Viçosa, v.21, n.2, p.241-7, 1997.

EMPRESA BRASILEIRA DE PESQUISA AGROPECUÁRIA. Serviço Nacional de Levantamento e Conservação dos Solos. Manual de métodos de análises de solo. Rio de Janeiro: Ministério da Agricultura, 1979. não paginado.

EMPRESA BRASILEIRA DE PESQUISA AGROPECUÁRIA. Sistema brasileiro de classificação de solos. Rio de Janeiro: Ministério da Agricultura e do Abastecimento, 1999. 412 p.

ERICKSON, A.E. Tillage effects on soil aeration. In: ANNUAL MEETING OF THE AMERICAN SOCIETY OF AGRONOMY, 1984, Madison. p.91-104. (Special Publication, 44)

FORSYTHE, W.M. Densidad de las partículas del suelo: método com água. Turrialba: IICA, 1971. $14 \mathrm{p}$.

HAKANSSON, I.; VOORHEES, W.B. Soil compaction. In: LAL, R.; BLUM, W.H.; VALENTIN, C. (Ed.). Methods for assessment of soil degradation. Boca Raton: Lewis, 1997. p.167-79.

KLEIN, V.A.; LIBARDI, P.L.; SILVA, A.P. Resistência mecânica do solo à penetração sob diferentes condições de densidade e teor de água. Engenharia Agrícola, Jaboticabal, v.18, n.2, p.45-54, 1998.

KLUTE, A. Water retention: laboratory methods. In: KLUTE, A. (Ed.). Methods of soil analysis. 2.ed. Madison: American Society of Agronomy, 1986. p.635-62.

LEITE, J.A. Influência dos sistemas de manejo sobre os atributos físicos e físico-hídricos de um Latossolo Amarelo (Typic Haplortox). 1996. 37 f. Tese (Livre-Docência em Manejo e Conservação do Solo e da Água) - Universidade do Amazonas, Manaus, 1996.

LEITE, J.A.; MEDINA, F.B. Efeito dos sistemas de manejo sobre as propriedades físicas de um Latossolo Amarelo do Amazonas. Pesquisa Agropecuária Brasileira, Brasília, v.19, n.8, p.1417-22, 1984.

LONGO, R.M. Modificações em parâmetros físicos e químicos de Latossolos argilosos decorrentes da substituição da Floresta Amazônica e do Cerrado por pastagens. 1999. 102 f. Tese (Doutorado em Água e Solo) - Universidade Estadual de Campinas, Campinas, 1999.

MEDINA, H.P. Água no solo. In: MONIZ, A.C. (Ed.) Elementos de pedologia. São Paulo: Meridional, 1980. p.45-7. 
MELLO IVO, W.M.P.; MIELNICZUK, J. Influência da estrutura do solo na distribuição e na morfologia do sistema radicular do milho sob três métodos de preparo. Revista Brasileira de Ciência do Solo, Viçosa, v.23, n.1, p.135-43, 1999.

PETERSON, R.A. O fator água. In: Fundamentos de manejo de pastagens. São Paulo: Instituto de Zootecnia da Secretaria da Agricultura, 1970. p.63-75.

REICHARDT, K. Processos de transferência no sistema solo-planta-atmosfera. Piracicaba: CNENFundação Cargill, 1975. 268 p.

REICHARDT, K.A. A água em sistemas agrícolas. São Paulo: Fundação Cargill, 1987. 188 p.

RODRIGUES, T. E.; MORIKAWA, I. K.; REIS, R. S.; FALESI, I. C. Solos do Distrito Agropecuário da SUFRAMA. Manaus: IPEAOC, 1971. 99 p. (Série solos, v.1, n.1).

SALIRE, E.V.; HAMMEN, J.E.; HARDCASTLE, J.H. Compression of intact subsoil under shortduration loading. Soil Tillage Research, Oxford, v.31, n.2-3, p.235-48, 1994.

SANCHEZ, P. A. Suelos del trópicos: características y manejo. San José: IICA, 1981. 634 p.

SILVA, I.F.; MIELNICZUK, J. Avaliação do estado de agregação do solo afetado pelo uso agrícola. Revista Brasileira de Ciência do Solo, Campinas, v.21, n.1, p.313-19, 1997.

TREIN, C.R.; COGO, N.P; LEVIEN, R. Métodos de preparo do solo na cultura do milho e ressemeadura do trevo, na rotação aveia + trevo/milho, após pastejo intensivo. Revista Brasileira de Ciência do Solo, Campinas, v.15, n.1, p.105-11, 1991.

VETTORI, L. Métodos de análises de solo. Rio de Janeiro: Ministério da Agricultura, 1969. 24 p. (Boletim Técnico, 7) 